\title{
Cognitive Processes Associated with the Perception of Randomness
}

\author{
Jacob M. Schreiber \\ Correspondence: Jacob M. Schreiber, 5 Sharet Street, Ramat-Gan, Israel. Tel: 972-3-6734060. E-mail: \\ ora1963@gmail.com
}

Received: August 28, 2013

Accepted: October 24, 2013

Online Published: March 12, 2014

doi:10.5539/jedp.v4n1p84

URL: http://dx.doi.org/10.5539/jedp.v4n1p84

\begin{abstract}
In a study of novice teachers' I investigate the conception of randomness among teachers college trainees that study probability and statistics. I gave the students questionnaires which serve to explored their conception and problem-solving approach with respect to probability problems, conception of randomness and deciding about the randomness of sequences and arrays, solving a THOG type problem, which raise the use of matching biases characteristics. I will show that the students use a set of rules to solve these different categories of problems. There is a common heuristic for all or many of these problem solving categories: the problem solver relay on heuristics anchored on the symmetry and asymmetry of sets of objects or more abstract elements to decide on questions like what is the probability of getting a certain sample in a random drawing of beads, the randomness of an array; certain sequences are measured by looking at the amount of apparent order in-order to make decisions concerning randomness and deviation from symmetry of the sample also effect the decision. This characteristic heuristic approach of problem solvers is founded on a set of simple rules relating to order, deviation from symmetry, the distribution of patches in the plane and occurrence of ordered subsequences in certain linear arrangement of sequences.
\end{abstract}

Keywords: asymmetry, cognition, conception, mechanism, perception, probability, sampling, symmetries, thog, randomness

\section{Introduction}

The cognition of chance, probability and randomness are often confused and appear to be unrelated. However, many times all three concepts are linked to a single cognitive process and to the occurrence of a certain event or events and are part of the process or characterized by it. Chance in many instances is associated with the perception of the likelihood of a single characteristic event or a series of independent events, and randomness is associated with order and arrangement of objects. Probability has a clear mathematic definition but not a clear linguistic use by novices or experts. It is often associated with a process, with certain events or repeated events (e.g., Bernoulli distribution, poisson process, sampling from a large population, certain chaotic processes such as the construction of the Sierpinski triangle in the "chaos game" Barnsley, 1993) and with the occurrence of certain clear events as part of process. There are some important consequences to the perception of randomness. If we believe something or some process is random we treat it in a different manner than if it wasn't such an event or process. Psychologists have been attempting to unravel the subjective conception of randomness and have come up with a variety of conflicting rules, conceptions and perceptions people have and use with regard to random events. They have been using a variety of methods to investigate the subjective conception of randomness (Falk, 1997; Eagle, 2005).

Often single chance objective events are linked to random processes incorrectly. If the outcome of the throwing of a fair coin is associated with the construction of a square array then almost everyone has an intuitive idea about the nature of the resulting pattern in the array. For example, this array 


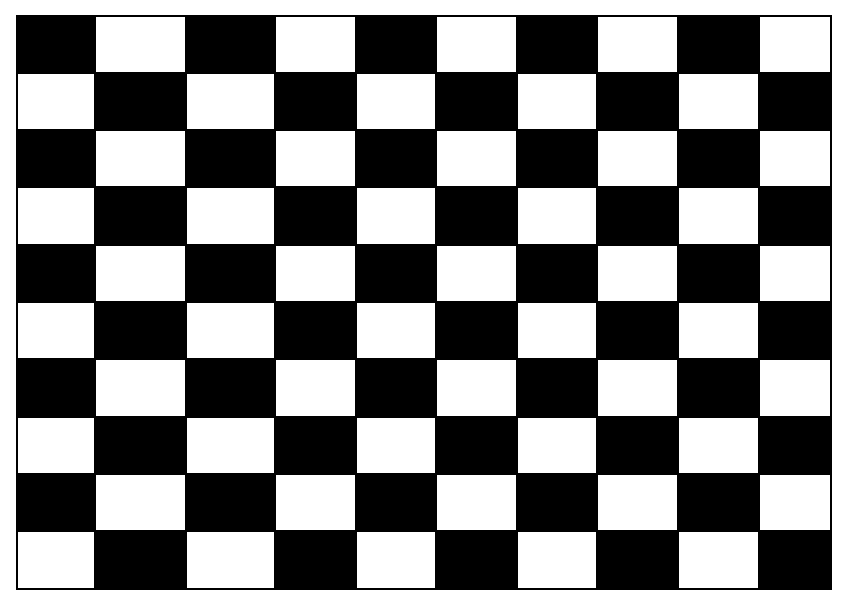

is perceived to have a less random arrangement then this array (Falk, 1997).

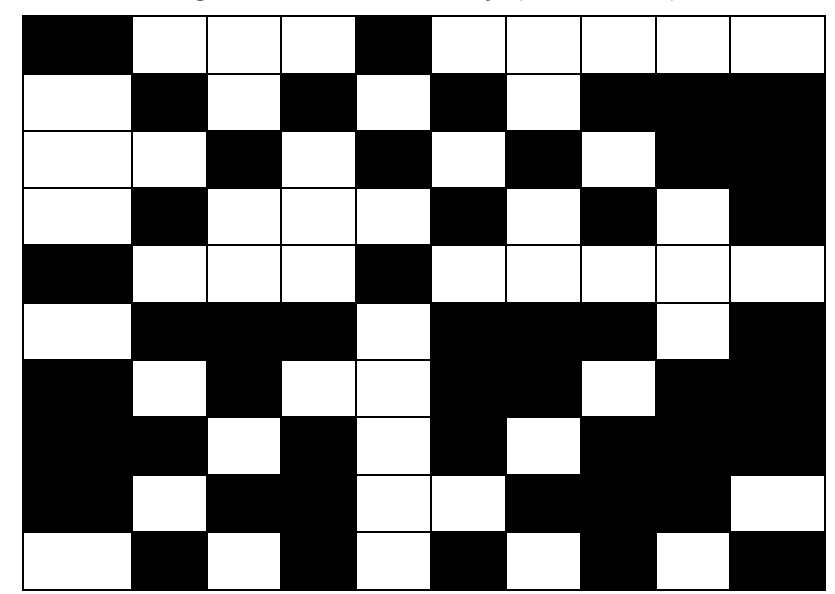

Although, both arrays were obtained by the same event process (e.g., throwing a fair coin). Many times the explanation given is that the second array is less ordered or that it is less symmetric in its appearance and it is more disordered. The following heuristics are actually being applied: More order less randomness, Less order more randomness. The rule is intuitively strong and the process by which the arrays are obtained is almost totally ignored. Another characteristic of the decision making for two dimensional arrays is the high relevance of the symmetry of the array to the decision making process. In many instances the heuristics applied in deciding whether the structure obtained is a random arrangement has to do with the symmetries of the structure: More symmetry less randomness, Less symmetry more randomness. The heuristics of more symmetry less randomness is also a characteristic of many probability problems solving decision making (Schreiber, 2012). The heuristics being applied is making the decision processes in two dimensions much more informal then the decision making for one dimension random sequences and it is extremely coercive.

People speak about randomness all the time and they discuss it in everyday and academic affairs but it is actually a hard to pin down concept that defies a clear definition. Many attempts at a definition of randomness were made by mathematicians and researchers (Eagle, 2005; Hellman, 1978; Kolmogorov, 1967). For example, in many instances a sequence is considered random if it is incompressible and has to be spelled out for full information. As far as the subjective perception of people array randomness is related to the clustering of color patterns and symmetries of the array; the more unordered color clusters it has the less random it is perceived and the less orderly the array is the more random and chaotic it is perceived.

In this article I focus on the subjective perception of randomness people have with regard to binary sequences, binary arrays and the subjective perception regarding certain sets of objects called THOGS. They are defined as certain geometric shapes in which either the color or shape property is being selected by the experimenter (Wason, 1977). They serve to unravel the heuristics processes used in problem solving in which probabilistic considerations are subtle, as in the THOG problem. THOGS and their elusive effects on problem solving as well as other selection tasks were studied by (Griggs \& Cox, 1982; Griggs \& Newstead, 1983, Grigg \& Newstead, 
1992). In these situations the symbol type and objects are equi-probable. I also report on several probability questions I gave to students and how the symmetric and asymmetric number of objects used for questioning has influenced their subjective problem solving. I report on the results of questionnaires I gave to novice teachers trainees. I use these results to show how subjective symmetry conception and randomness are related, specifically using a variety of rules and heuristics people apply to solve probability problems and their subjective perceptions of randomness. Random processes are often related by people to chaotic results and thus associated with result such as "less order more randomness" mentioned above, but this subjective perceptions are unjustified. I will also explore the complex relationship between symmetry and randomness in terms of the rules students use to solve problems.

\subsection{Rules for Estimating Probabilities from Numerically Symmetric and Asymmetric Object Arrangements}

There are many rules intuitions and heuristics used for solving problems in general and estimating probabilities in particular and they are apparent in the analysis of cognitive processes and are manifested in the use of rules for estimating probabilities, randomness, randomness of sequences and the randomness of arrays. It could be observed and inferred that students use certain heuristics and intuitive rules to answer these questions.

Some of the probability rules were described in Schreiber (2012). This section contains several of the rules mentioned in the research and used by students. In the literature intuitive rules are characterized as "intuitive" or "heuristics". Here each rule is characterized by its original name. The rules presented are related to probability estimation in a unified and uniform probability space.

\section{A. Asymmetry - Numerical difference among the objects}

This rule described in a previews research (Schreiber, 2003) is set into action when it is known that there are more objects of one kind compared with the other. The rule is: "When there is a group of objects (A,B,C,D ...) in a unified probability field and a pair is being drawn at random if A has the largest frequency the probability of drawing a pair AA is the largest". This rule has several variations according to the numerical differences among the objects and their relations: Numerical asymmetry among the dominant objects and asymmetry among sub-components (asymmetry of the second kind).

\section{B. Symmetry - numerical equality of the objects being sampled}

The rule is activated when there is the same number of objects of two types being considered. The rule is: "When in a group of objects there are numerically the same number of objects type A and B and two are drawn at random the probability is greater that one of each type will be drawn, a pair AB". This rule has variations when there are several types of object arrangements.

A. Rules for estimating probabilities from sets of objects containing numerically asymmetric sets of objects containing numerically asymmetric sets of objects

1) Numerical difference rule - Asymmetry: "If there are more objects of one type the probability of drawing two beads of that type on a random drawing of pairs is the greatest."

1a. Numerical difference rule - Asymmetry of the second type: "If there are more objects of one type (not necessarily numerically the largest type). The probability of drawing a pair of objects of that type is larger than the probability of drawing a pair of the other objects.

1b. Summation rules: "If the sum of two types of objects is greater than any other type or any combination of other objects, the probability of drawing a pair of this type is larger compared to the probability of drawing pairs of objects from the other objects.

1c. The pair rule: if the number of pairs of objects in a group is greater than the number of the other pairs the probability of drawing a pair of that kind is greater than drawing pairs of the other kind.

There is a variation of the "pair rule" suitable for numerically symmetric sets of objects. "If the number of pairs of two types of objects is equal, the probability of drawing a pair of objects, one object of each type, is equal."

B. Rules for estimating probabilities when drawing pairs of objects from approximately numerically symmetric sets of objects

2) Numerical Symmetry: If the bag contains the same number of objects of different types $(a=b \geq c \ldots)$, the probability of drawing two items in different color is larger than the probability of drawing a pair of objects from the other bags.

2a. Numerical Symmetry of the Second Order: If a bag contains the same number of objects of different types $(\mathrm{a} \geq$ $\mathrm{b}=\mathrm{c} \ldots$...) the probability of drawing two items with different colors is larger than the probability of drawing a pair 
of objects from the other bags, given that in the other bags the number of objects is large (more than 50 or 100 in a bag), and even if there is a numerical equality of objects in the other bags.

The main characteristic of students estimating probabilities in this group is that they think there is a much higher probability of drawing a pair of beads, one in each color, from numerically symmetric sets of objects compared to numerically larger asymmetric sets of objects. The intuition associated with the symmetric set of objects is strong and the chances of drawing a symmetric set of object from it is considered much more likely compared with a set of asymmetric set of objects.

$2 b$. There are two different types of objects with equal number of beads and numerically they are the highest number in a set of beads:

If the bag contains the same number of beads of different types and the arrangement of objects is $(a=b \geq c \ldots)$, the probability of drawing two beads with different colors is larger than the probability of drawing a pair of beads from the other bags, given that they contain less than 50 beads in a bag (this is consistent with the structure of the questions in the present research, the answers students gave, and not presented as a general rule used by students).

The main characteristic of students estimating probabilities in this group is that when they use the rules they think that there is a much higher probability of drawing a pair of objects, one in each color, from the larger set of objects compared with sets that have numerically smaller number of objects.

\section{Methodology}

The population in this research is composed of students studying to be mathematics teachers in an educational college in Israel. Most have studied probability and statistics. Many of them are working as mathematics teachers while studying for their college degree.

\subsection{The Research Question}

What are the characteristics of estimating randomness?

In this research I plan to describe qualitatively the way problems associated with symmetric and asymmetric array arrangements are perceived and solved for randomness questions by novice teachers.

\subsection{The Research Assumptions}

1) Symmetry of color and shape assumption: THOGS are perceived to have similar geometric shapes or colors to other known THOGS.

2) Symmetric array arrangements are judged less random by students.

3) Samples from symmetric set of object arrangement is perceived to have an equal probability of occurrences.

4) Asymmetric array arrangements are judged to have more randomness.

5) Samples from asymmetric set of object arrangement is perceived to have an-unequal probability of occurrences.

\subsection{The Independent Variables}

Student characteristics: Teacher college students: first year and third year students; probability and statistics education, two groups: studied probability and statistics, did not study probability and statistics. Grades in the classes that were tested: high grades, medium grades, low grades.

Gender: Men, Women.

Object sets. a. Geometric figures and colors associated with figures, b. Sequences of zeros and ones, c. Arrays of black and white squares, d. The number of objects and numerical relations among the types of objects being pulled out of a bag with beads, and the number of sets in the population. Group A-contains questions relating to asymmetric sets of objects (the asymmetry set). Group B-contains questions relating to symmetric sets of objects (the symmetry set).

Asymmetry. Numerically in a set of beads high distance is defined as a distance greater than three beads, a small distance is a distance of one. In an array asymmetry is defined as a break of geometric equivalence. In a sequence of zeros and ones asymmetry is defined as a disorder in arrangement. A continuous sequence 1010...is symmetric while a continuous sequence $1101011010 \ldots$ is less symmetric in the sense that it requires more information to describe the sequence repetitive characters. 
Symmetry. The symmetry is larger when the numerical difference in a set of beads is zero and less when the numerical distance is one or two. The symmetry in a set of ones and zeros is larger when disorder of one and zeros is minimal, and when array arrangement of black and white squares is geometrically equivalent.

\subsection{The Dependent Variable}

The rules, strategies and consistency of using rules and strategies when solving probability problems, judging randomness of sequences and arrays, comparing shapes geometric figures and colors of figures in conjunction.

\subsection{Research Design}

The design was built to verify the research question with respect to the different set of objects-numerically symmetric and asymmetric set of objects. For that purpose the structure of the data was manipulated in order to reveal students strategies for solving probability problems, strategies for estimating randomness of arrays and sequences, heuristics applied for solving problems (the THOG problem).

The idea was that similar strategies, heuristics and intuitions are being applied to solve a variety of apparently different sets of problems. By asking questions in a variety of different subjects we will be able to show that a variety of similar heuristic methods is being applied to solve probabilistic and pseudo-probabilistic (e.g., THOG \& Wason, 1977) problems in different areas of questioning.

The classical THOG problem (Wason, 1977; Smyth \& Clark, 1986) and the current version is an inherently probabilistic problem which students do not usually recognize as such. The random sequences and array problems are also probabilistic in nature and require probabilistic methods for solution, but in all these varying questions students tend to predominately apply heuristics for solving the problems and use less appropriate analytic methods.

\subsubsection{Research Tools}

There were two similar questionnaires. The first contains the THOG problem, random sequences problem, random array problem, probability problems answered by third year students. The second contains the THOG problem, random array problem, probability problems answered by answered by first year students. The questions are about randomness and probabilities, subtle or hidden probabilities; it has to do with estimating the randomness of sequences and arrays and deciding which geometric shape is in a certain category named THOG. There are direct probability questions about the random drawing of beads from bags without seeing the content of the bag. The questions are about the colors of beads, at random, or about choosing a bag from which the probability of choosing a pair of beads one red and one green, at random is with higher probability.

\section{The Questions:}

\section{The THOG problem}

1) Look at the following geometric shapes. Assume I have written on a piece of paper the name of one of the shapes and color of one of the shapes. If and only if a figure contains the shape I have chosen or the color but not both it is called THOG. I will tell you that the black diamond is a THOG. What can be said about the other shapes? Are there any more THOGS? 

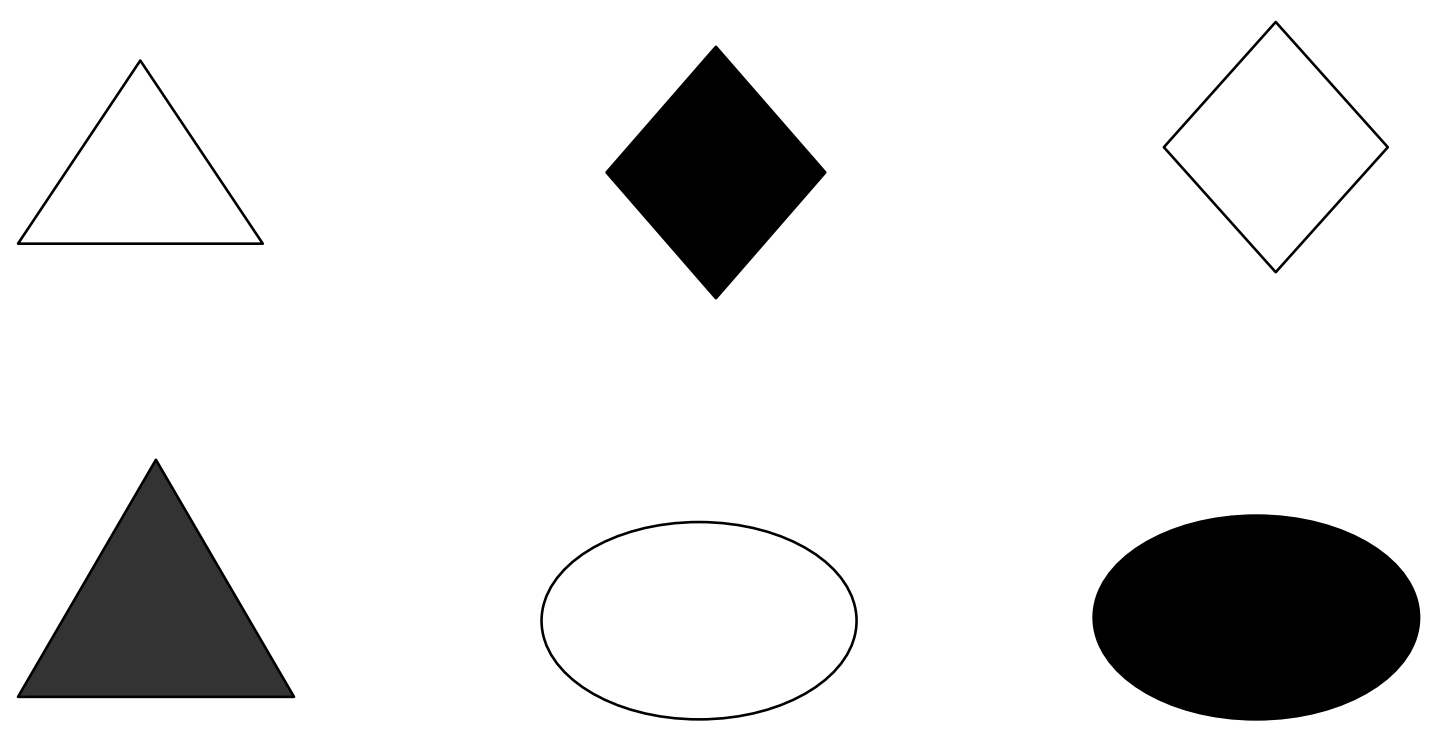

We know that the black diamond is a THOG so either I wrote down black or diamond, not both. If I wrote color black the shape I have written down must have been ellipse or triangle, I could not have written down diamond. Therefore, if I had written down black and ellipse the white ellipse and white triangle are THOGS. But, if I have written down black and triangle the white triangle and black ellipse are THOGS. If I wrote down diamond the color I have written down must have been white and therefore, the white triangle and white ellipse are THOGS. The deductive process shows that there could be another THOG but we cannot decide on the problem because there is no sufficient information.

\section{Probability questions}

1) The bag contains 5 red beads, and 2-green beads. We want to randomly draw a pair of beads. For each situation described you are requested to say if the sentence is correct or not.

2) The probability that in a random drawing from the bag two red beads are drawn is greater than the probability of drawing two beads one red and one green. True: False.

The probability of drawing two red beads is:

$P(2-$ red $)=\frac{5}{7} \times \frac{4}{6}=\frac{10}{21}$

The probability of drawing one red bead and one green bead is given by:

$P($ red.\&.green $)=\frac{5}{7} \times \frac{2}{6}+\frac{2}{7} \times \frac{5}{6}=\frac{10}{21}$

3) Three bags contain beads: the first contains 5 red beads and 4 green beads, the second contains 5 red and 5 green beads, and the third contains 4 red beads and 5 green beads.

From which bag the probability of randomly choosing two beads one red and one green, is the largest?

Consider the first and third bag. The probability of drawing two beads, one green and one red, is given by:

$P($ red.\&.green $)=\frac{5}{9} \times \frac{4}{8}+\frac{4}{9} \times \frac{5}{8}=\frac{5}{9}$

while the probability of drawing two beads, one green and one red, from the second bag is:

$P($ red.\&.green $)=\frac{5}{10} \times \frac{5}{9}+\frac{5}{10} \times \frac{5}{9}=\frac{5}{9}$

Randomness questions concerning sequences and arrays appear in the questionnaires section.

\subsubsection{Data Analysis}

Checking the research assumption and the rate students are using the rules and heuristics. 
The fitting of students' answers to the research assumptions is based on a student's answers to the written test, not taking into account calculations any estimations and rules in any way.

\section{Findings}

The findings are characterized by the informal rules and heuristics that were used by students (a. third year teacher trainees, b. first year teacher trainees) to answer the questions and estimate probabilities from numerically symmetric and asymmetric sets of objects, arrays, and their answers to the pseudo- probabilistic THOG problem.

\subsection{The Written Questionnaire}

The questionnaire was distributed in class, answered and collected by me within 30 minutes. The subjects carried out the task individually. The main points that came up from analyzing the answers in the written test are summarized below:

A. The THOG problem. Among students answering the THOG problem (third year teacher trainees) 21 out of $26.81 \%$ have found more THOGS. Table 1 . Most students point out similarity of shape and color as reason for having found more THOGS. Judgment is heuristic and the influence of symmetry is strong. The probabilistic structure of the problem is not apparent to most students and therefore reasoning is purely a heuristic function based on color shape or visual similarity. Among students answering the THOG problem 21 out of $26.81 \%$, have found that the white diamond is a THOG, which can be shown to be an impossible situation when the black diamond is a THOG.

Table 1. The THOG problem (third year teacher trainees, studied probability and statistics)

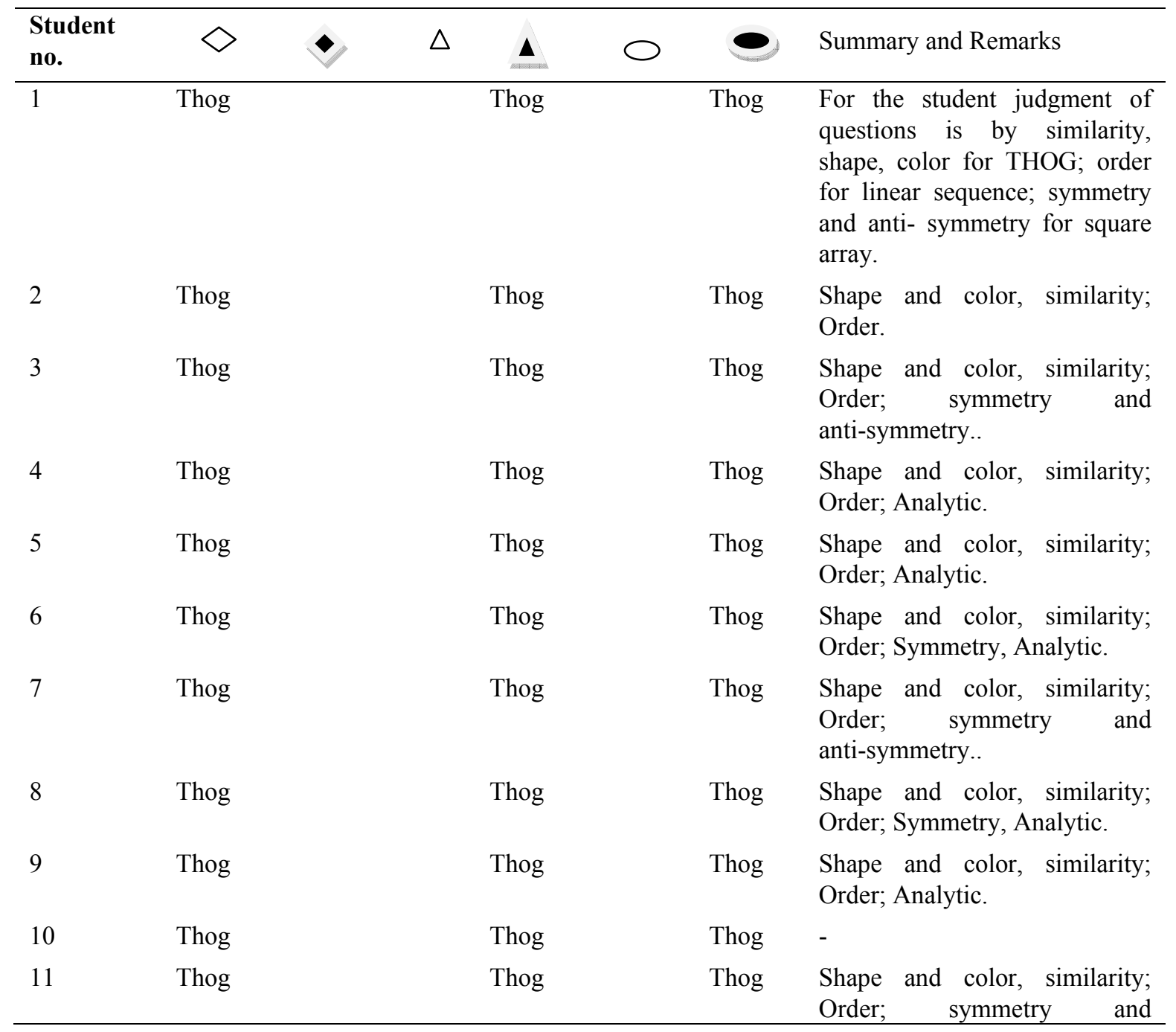




\begin{tabular}{|c|c|c|c|c|c|}
\hline & & & & & anti-symmetry. \\
\hline 12 & Thog & Thog & & Thog & $\begin{array}{l}\text { similarity; order; symmetry and } \\
\text { anti-symmetry. }\end{array}$ \\
\hline 13 & Thog & Thog & & Thog & $\begin{array}{l}\text { Shape and color, similarity; } \\
\text { order symmetry and symmetry, } \\
\text { analytic. }\end{array}$ \\
\hline 14 & Thog & Thog & & Thog & $\begin{array}{l}\text { Shape and color, similarity; } \\
\text { symmetry and anti-symmetry. }\end{array}$ \\
\hline 15 & Thog & Thog & & Thog & $\begin{array}{l}\text { Shape and color, similarity; } \\
\text { anti-symmetry. }\end{array}$ \\
\hline 16 & Thog & Thog & & Thog & $\begin{array}{l}\text { Similarity, shape, color; } \\
\text { anti-symmetry }\end{array}$ \\
\hline 17 & Thog & Thog & & Thog & Similarity and anti-symmetry \\
\hline 18 & Thog & - & & - & $\begin{array}{l}\text { For the student judgment of } \\
\text { questions is by shape, color for } \\
\text { thog; order for linear sequence; } \\
\text { symmetry for square array. }\end{array}$ \\
\hline 19 & - & & & & order \\
\hline 20 & - & & & & - \\
\hline 21 & - & & & & symmetry \\
\hline 22 & Thog & Thog & & Thog & similarity \\
\hline 23 & - & & & & - \\
\hline 24 & - & & & & $\begin{array}{l}\text { For the student judgment of } \\
\text { questions is by shape, color for } \\
\text { thog; symmetry for linear } \\
\text { sequence; symmetry for square } \\
\text { array. }\end{array}$ \\
\hline \multirow[t]{2}{*}{25} & Thog & & Thog & Thog & $\begin{array}{l}\text { We need to mark a shape that is } \\
\text { rhombus or black. }\end{array}$ \\
\hline & & & & & $\begin{array}{l}\text { Judgment is by color and shape; } \\
\text { and he is analytic. }\end{array}$ \\
\hline 26 & Thog & Thog & & Thog & Shape and color, similarity \\
\hline
\end{tabular}

Note: Among students answering the THOG problem. 21 out of $26.81 \%$ have found more Thogs. Most students point out similarity of shape and color as reason for having found more THOGS. Judgment is heuristic and the influence of symmetry is strong. The probabilistic structure of the problem is not apparent to most students and therefore reasoning is purely a heuristic function based on color shape or visual similarity.

Most students answering the THOG problem (first year teacher trainees) point out the similarity of shape and color as reason for having found more THOGS. Judgment is heuristic and the influence of symmetry is strong. The probabilistic structure of the problem is not apparent to most students and therefore reasoning is purely a heuristic function based on color, shape or visual similarity. 11 out of $16.69 \%$, have found more THOGS. Table 2. Among students answering the THOG problem 9 out of $16,56 \%$, have found that the white diamond is a THOG, which can be shown to be an impossible situation when the black diamond is a THOG. 
Table 2. The THOG problem (First year teacher trainees, did not study probability and statistics in college).

\begin{tabular}{|c|c|c|c|c|c|c|c|}
\hline $\begin{array}{l}\text { Student } \\
\text { no. }\end{array}$ & $\diamond$ & $\bullet$ & $\triangle$ & $\Delta$ & 0 & 0 & Explanetion \\
\hline 1 & Thog & & & Thog & & Thog & $\begin{array}{l}\text { There are } 3-\text { thogs, two in } \\
\text { figure, 1- in shape. }\end{array}$ \\
\hline \multicolumn{8}{|l|}{2} \\
\hline 3 & Thog & & & Thog & & Thog & - \\
\hline 4 & Thog & & & Thog & & Thog & - \\
\hline 5 & Thog & & & Thog & & Thog & All are thogs \\
\hline 6 & & & & & & & Yeas there are more thogs \\
\hline \multicolumn{8}{|l|}{7} \\
\hline 8 & Thog & Thog & Thog & Thog & Thog & Thog & All are thogs \\
\hline 9 & & & & Thog & & Thog & The triangle and ellipse \\
\hline \multicolumn{8}{|l|}{10} \\
\hline 11 & & & & Thog & & Thog & All black figures are thogs \\
\hline 12 & Thog & & & Thog & & Thog & \\
\hline 13 & & Thog & & & & & \\
\hline 14 & Thog & & & Thog & & Thog & - \\
\hline 15 & Thog & Thog & Thog & Thog & Thog & Thog & All are thogs \\
\hline 16 & Thog & Thog & Thog & Thog & Thog & Thog & - \\
\hline \multicolumn{8}{|l|}{17} \\
\hline \multicolumn{8}{|l|}{18} \\
\hline \multicolumn{8}{|l|}{19} \\
\hline \multicolumn{8}{|l|}{20} \\
\hline \multicolumn{8}{|l|}{21} \\
\hline \multicolumn{8}{|l|}{22} \\
\hline \multicolumn{8}{|l|}{23} \\
\hline \multicolumn{8}{|l|}{24} \\
\hline \multicolumn{8}{|l|}{25} \\
\hline \multicolumn{8}{|l|}{26} \\
\hline & $9 / 16$ & & & $11 / 16$ & & $11 / 16$ & \\
\hline
\end{tabular}

Note: Here also most students point out similarity of shape and color as reason for having found more thogs. Judgment is heuristic and the influence of symmetry is strong. The probabilistic structure of the problem is not apparent to most students and therefore reasoning is purely a heuristic function based on color shape or visual similarity.

B. Random Sequences (Third year students). The selection of the most random array is no. 4-(4,2,3,5,1), 25 out of $26.96 \%$, and the least random is no. 1,22 out of $26.85 \%$. The selection of that sequence is clearly a choice biased towards disorder among the elements. See section 3.2.2 for rules heuristics for solving problems and estimating randomness.

C. Random Square Arrays (Third year students). The selection of the most random array is no. 3, 15 out of $26.57 \%$, no. 2 , 4 out of $26,15 \%$, and the least random is no. 1,19 out of $26.73 \%$. The selection of no. 1 $3,2,5,4,6,1$ is probably a choice biased towards disorder among the elements; that array has a deviation from symmetry. 
Random Square Arrays (First year teacher trainees). The selection of the most random array is 3,2,5,4,6,1 or $3,2,5,6,4,119 \%(3 / 16), 31 \%(5 / 16)$ claim that randomness is unknown and $13 \%(2 / 16)$ claim that the probability for a random arrangement is equal in all arrays.

D. 1) Answers to probability questions (Third year teacher trainees, Table 6). Most often students select the "true" answer because the bag contains more red beads, thinking more red implies more probability, and they select the second bag because it has equal number of red and green beads-selecting a symmetric structure. Applying the intuitive rule "Same A Same B". The same number of beads the same probability of drawing a pair.

2) Answers to probability questions (First year teachers- statistics class, Table 7). Most often students select the "true" answer because the bag contains more red beads thinking more red implies more probability, and they select the second bag because it has equal number of red and green beads- selecting a symmetric structure. For more on intuitive rules see also the section on rules and heuristics for solving problems and estimating probabilities in the introduction.

\subsection{Summing up Findings for Sequence Randomness and Array Randomness}

Sequence Randomness. As indicated, the answers for the randomness of sequences given by third year students were characterized by the selection of the most random sequence to be number sequence number 4-expressed usually as the more favorable by selecting the sequences from left to right $(4,2,3,5,1), 25$ out of $26.96 \%$, while the least random sequence is number 1 on the right, 22 out of $26, \mathbf{8 5 \%}$. The rule being used by students is probably "More order less Randomness" and "Less order more Randomness". This is consistent with (Hellman, 1978, p. 83).

Array Randomness. As indicated for third year students, the selection of the most random array is number 1, 15 out of $26.57 \%$, array number 2,4 out of $26,15 \%$, and the least random is number 1,19 out of $26.73 \%$. The selection of array number 1 right to left - $(3,2,5,4,6,1)$ is probably a choice biased towards disorder among the elements, selecting an array that has a structure with the largest deviation from symmetry.

For first year teacher trainees the selection of the most random array is $(3,2,5,4,6,1)$ or $(3,2,5,6,4,1) 19 \%(3 / 16)$, $31 \%(5 / 16)$ claim that randomness is unknown and $13 \%(2 / 16)$ claim that the probability for a random arrangement is equal in all arrays.

\section{Discussion}

According to Evans (2003) people have two separated cognitive systems. One is old in evolutionary terms (system 1) and is also prevalent among animals; it includes a set of autonomic sub-systems that includes inborn traits and domain-specific knowledge. The other is human in nature and characterizes human thinking (system 2). The characteristics of third year students as well as first year students is the use of system 1 for solving probability problems. People tend to see symmetry and translate it to perceptual symmetry and asymmetry (MacBeth, Schiano $\&$ Tversky, 1977). The sensitivity to symmetry of the human visual system in general and that of novice teachers when solving probability problems and estimating randomness is prevalent in this research. It is related to the use of rules and heuristics for solving probability problems and deciding on the relative order, symmetry and arrangement of beads in shuffled bags and the randomness of sequences and arrays. For many students estimating and solving simple probability problems of physical type (e.g. drawing beads from bags, throwing a fair coin) or solving for Bernoulli type experiments have the characteristic that the solution of the problem is associated with chance and not with logical or theoretical probabilities Anscombe \& Aumann (1963). The selection of rules for estimating probabilities is related to the deviation from symmetry Schreiber (2012). The answers students gave to the randomness problem in this research is related to the deviation of order and coherence of sets of objects and the deviation of sets of objects from symmetries. Students' thinking is heuristically best described by rule "the more order the less randomness" for sequences and arrays. Students also relay on visual symmetry when solving the THOG problem and they disregard the subtle probabilistic nature of the THOG problem and its inner probabilistic logic preferring to concentrate on certain matching characteristics of the problem; this problem solving approach is known as matching bias Evans (1982). In this approach people tend to see two things as similar to the extent that they share common features. If told that the black diamond is a THOG then the participants will think that a figure is a THOG to the extent that it matches the black diamond Griggs \& Newstead (1983). The white diamond, the black circle and black triangle have such common features, Table 1 , Table 2.

There are several related findings for such heuristics in the literature. For example "Less order more Randomness" is consistent with Hellman (1978, p. 83) that "physically random" is "roughly interchangeable with "in-deterministic"". Indeterministic means that the complete and correct scientific theory of the process is 
in-deterministic. According to Eagle (2005), randomness is maximal unpredictability. First year students are making similar choices using the heuristics "Less order more randomness". The selection of the most random sequence is clearly a choice biased towards disorder among the elements, Table 3 . The concept of disorder is an intrinsic notion; it cares nothing about the genesis of the sequence and relates to a pattern a sequence might have or not have. By contrast randomness is related to the genesis of the sequence and asks whether the sequence reflects the probabilities of the process that generates the sequence. It appears that cognitively there is a strong connection between randomness and disorder but mathematically there is no such tight connection Earman (1986).

Table 3. Random sequences (third year students)

\begin{tabular}{|c|c|}
\hline Student no. & $\begin{array}{l}\text { Randomness of sequences arranged } \\
\text { left to right. } \\
\text { The most rendom is on the left. }\end{array}$ \\
\hline 1 & $4,2,3,5,1$ \\
\hline 2 & $4,2,3,5,1$ \\
\hline 3 & $4,2,3,5,1$ \\
\hline 4 & $4,2,3,5,1$ \\
\hline 5 & $4,2,3,5,1$ \\
\hline 6 & $4,2,3,1,5$ \\
\hline 7 & $4,2,3,1,5$ \\
\hline 8 & $4,2,3,5,1$ \\
\hline 9 & $4,2,3,5,1$ \\
\hline 10 & $4,2,3,5,1$ \\
\hline 11 & $4,2,3,5,1$ \\
\hline 12 & $4,2,3,5,1$ \\
\hline 13 & $4,2,3,5,1$ \\
\hline 14 & $4,2,3,5,1$ \\
\hline \multirow[t]{2}{*}{15} & $4,2,3,5,1$ \\
\hline & Numbers are arranged in specific order \\
\hline 16 & $4,3,2,5,1$ \\
\hline 17 & $4,2,3,5,1$ \\
\hline 18 & $4,3,2,1,5$ \\
\hline 19 & $4,2,5,3,1$ \\
\hline 20 & $4,2,5,3,1$ \\
\hline 21 & $4,2,3,1,5$ \\
\hline 22 & $4,2,3,5,1$ \\
\hline \multirow[t]{2}{*}{23} & $4,3,2,5,1$ \\
\hline & Order and continuity \\
\hline 24 & $4,2,3,5,1$ \\
\hline 25 & $4,2,3,5,1$ \\
\hline \multirow[t]{2}{*}{26} & $4,2,3,5,1$ \\
\hline & $22 / 26.4,2,3,5,1$ \\
\hline
\end{tabular}

Note: The selection of the most random array is no. $4-(4,2,3,5,1), 25$ out of $26.96 \%$, and the least random is no. 1,22 out of $26.85 \%$. The selection of that sequence is clearly a choice of disorder among the elements. 
Table 4. Random square arrays (third year teacher trainees)

\begin{tabular}{|c|c|}
\hline Student no. & $\begin{array}{l}\text { Randomness of arrays arranged } \\
\text { left to right. } \\
\text { The most rendom is on the left. }\end{array}$ \\
\hline 1 & $3,2,5,4,6,1$ \\
\hline 2 & $2,3,5,6,4,1$ \\
\hline 3 & $4,6,1,3,2,5$ \\
\hline 4 & $3,2,5,4,6,1$ \\
\hline 5 & $3,2,5,4,6,1$ \\
\hline 6 & $2,3,5,6,4,1$ \\
\hline 7 & $2,3,5,6,4,1$ \\
\hline 8 & $3,2,6,5,4,1$ \\
\hline 9 & $3,2,5,4,6,1$ \\
\hline 10 & $3,2,5,6,4,1$ \\
\hline 11 & $3,2,6,5,4,1$ \\
\hline 12 & $3,2,5,6,4,1$ \\
\hline 13 & $3,2,5,4,6,1$ \\
\hline 14 & $2,3,5,1,4,6$ \\
\hline 15 & $3,2,5,6,4,1$ \\
\hline 16 & No answer \\
\hline 17 & $1,2,3,4,6,5$ \\
\hline \multirow[t]{2}{*}{18} & $3,2,6,5,4,1$ \\
\hline & $\begin{array}{l}\text { EXP: When the array is not } \\
\text { random the order is apparent, and } \\
\text { the random arrays are do not have } \\
\text { an apparent order }\end{array}$ \\
\hline 19 & $3,2,5,6,4,1$ \\
\hline 20 & No answer \\
\hline 21 & $5,3,2,4,6,1$ \\
\hline 22 & $3,2,5,4,6,1$ \\
\hline 23 & $1,2,5,4,6,1$ \\
\hline 24 & No answer \\
\hline \multirow[t]{2}{*}{25} & $3,2,5,4,6,1$ \\
\hline & EXP: By symmetry \\
\hline \multirow[t]{2}{*}{26} & $3,2,5,4,6,1$ \\
\hline & 9- $3,2,5,4,6,1$ \\
\hline
\end{tabular}

Note: The selection of the most random array is no. 3,15 out of $26.57 \%$, no.2, 4 out of $26.15 \%$, and the least random is no. 1,19 out of $26.73 \%$. The selection of no.1 - 3,2,5,4,6,1 is made because it has an apparent disordered arrangement, it has a deviation from symmetry.

For many authors (e.g. Kolmogorov 1967; KCS circa 1960's - stands for: Andrei Kolmogorov; Gregory Chaitin and Ray Solomonov) a sequence is random if it is incompressible and has to be spelled out, Eagle (2005). This is known as KCS randomness and defined by the complexity of sequences. For Example if the tossing of a coin results with $11100111011100101010 \ldots$ (1-head, 0 -tail) the sequence has to be spelled out for full information because patternlessness is incompressibility. But, the sequence $10101010101010 \ldots$ can be reported in a compressed form as repeated " 10 ". So for KCS sequential randomness is mathematically related to compressibility. KCS is concerned with the process of producing the shortest string but for arrays we are concerned with patterns and randomness not taking into account how the pattern evolves, i.e., history does not influence randomness. 
Definition 1 (KCS-RANDOMNESS). A sequence $\mathrm{S}$ is KCS-random if its complexity is approximately its length: $\mathrm{K}(\mathrm{S})=l(\mathrm{~S})$.

Definition 2 (COMPLEXITY). The complexity K(S) of sequence $\mathrm{S}$ is the length of the shortest program $C$ of some Turing machine $T$ which produces $S$ as output, when given as input the length of S, Eagle (2005). $K(S)$ is set to 1 if there does not exist a $C$ that produces $\mathrm{S}$.

However, there is no universal agreement on the mathematical definition of randomness. Hellman (1978) suggests that randomness is interchangeable with indeterminism while Ekeland (1988) says that the main feature of randomness is some degree of independence from initial conditions. Yet we know from chaos theories that performing experiments with the same initial conditions often leads to different results.

Array randomness. Falk $(1975,1997)$ has obtained the apparent randomness AR of a variety of sequences and grids showing that the apparent randomness is related to the clustering of color patterns of the array, the more color clustered grid perceived as least random. She obtained participant's randomness rating on a scale from 1 to 20 for sequences and for $10 \times 10$ binary grids cells. In the present research we see that choosing array arrangements $(1,6,4)$ in any order is the most common, showing that patches of colors (white or black) reduce apparent randomness. But more than that, increasing the order of the array elements as a function of the symmetry of the array reduces the apparent randomness, which in this research can be seen in array 1 the array first on the left in the subset $(1,6,4)$ while 6 is chosen second and more random in that set and more then array no. 4 in the third place. Clearly array 1 appears to students more ordered then array 6 and array 4 . It seems that the cognitive connection "order and less randomness" is strong and so is "symmetry and less randomness" but the sample here is too small to make a clear statement, certainly not enough to tell which cognitive connection is stronger, Table 5, Table 6. Many of the rules being used and observed are being summed up in Figure 1.

Table 5. Random square arrays (first year teacher trainees)

\begin{tabular}{ll}
\hline Student no. & $\begin{array}{l}\text { Randomness of arrays arranged } \\
\text { left to right (The most rendom is } \\
\text { on the left) }\end{array}$ \\
\hline 1 & $3,6,5,2,4,1$ \\
2 & - \\
3 & - \\
4 & All are equally random \\
5 & Equally probable \\
6 & - \\
7 & - \\
8 & Not Known \\
9 & $3,2,5,6,4,1$ \\
10 & Not Known \\
11 & - \\
12 & - \\
13 & Not Known \\
14 & $3,2,5,6,4,1$ \\
15 & Not Known \\
16 & Not Known \\
The most & $\mathbf{3 , 2 , 5 , 6 , 4 , 1}$ \\
prevalent & Or not known \\
answers & \\
were & \\
\hline
\end{tabular}

The selection of the most random array is $3,2,5,4,6,1$ or $3,2,5,6,4,119 \%(3 / 16), 31 \%(5 / 16)$ claim that randomness is unknown and 13\% (2/16) claim that the probability is equal in all arrays. 
Table 6. Answers to probability questions (third year teacher trainees)

\begin{tabular}{|c|c|c|c|c|c|c|}
\hline $\begin{array}{l}\text { Student } \\
\text { no. }\end{array}$ & $\begin{array}{l}\text { 5-RED, } \\
\text { 2-Green }\end{array}$ & Explenation & $\begin{array}{l}\text { 3-RED, } \\
\text { 1-Green }\end{array}$ & Explenation & $\begin{array}{l}\text { 5-RED, 4-Green; } \\
\text { 5-RED, 5-Green; } \\
\text { 4-RED, 5-Green }\end{array}$ & Explenation \\
\hline 1 & True & $\begin{array}{l}\text { The bag has } \\
\text { more red } \\
\text { beads }\end{array}$ & True & $\begin{array}{l}\text { The bag has } \\
\text { more red } \\
\text { beads }\end{array}$ & Second bag & Equal numbers \\
\hline 2 & Not true & $\begin{array}{l}\text { Written } \\
\text { explanation }\end{array}$ & Not true & $\begin{array}{l}\text { Written } \\
\text { explanation }\end{array}$ & Equal Chances & $\begin{array}{l}\text { Written } \\
\text { explanation }\end{array}$ \\
\hline 3 & True & - & True & - & Second bag & - \\
\hline 4 & Not true & $\begin{array}{l}\text { By } \\
\text { calculation }\end{array}$ & Not true & $\begin{array}{l}\text { By } \\
\text { calculation }\end{array}$ & Equal Chances & By calculation \\
\hline 5 & Not true & $\begin{array}{l}\text { By } \\
\text { calculation }\end{array}$ & Not true & $\begin{array}{l}\text { By } \\
\text { calculation }\end{array}$ & Equal Chances & By calculation \\
\hline 6 & True & $\begin{array}{l}\text { Written } \\
\text { explanation }\end{array}$ & Not true & $\begin{array}{l}\text { Written } \\
\text { explanation }\end{array}$ & Equal Chances & $\begin{array}{l}\text { Written } \\
\text { explanation }\end{array}$ \\
\hline 7 & True & $\begin{array}{l}\text { Written } \\
\text { explanation }\end{array}$ & True & $\begin{array}{l}\text { Written } \\
\text { explanation }\end{array}$ & Second bag & $\begin{array}{l}\text { Written } \\
\text { explanation }\end{array}$ \\
\hline 8 & True & $\begin{array}{l}\text { Written } \\
\text { explanation }\end{array}$ & Not true & $\begin{array}{l}\text { Written } \\
\text { explanation } \\
\text { Calculation }\end{array}$ & Second bag & $\begin{array}{l}\text { By calculation-it } \\
\text { has equal chance }\end{array}$ \\
\hline 9 & Not true & $\begin{array}{l}\text { By } \\
\text { calculation }\end{array}$ & Not true & $\begin{array}{l}\text { By } \\
\text { calculation }\end{array}$ & Equal Chances & By calculation \\
\hline 10 & - & & - & & Equal Chances & $\begin{array}{l}\text { Written } \\
\text { explanation }\end{array}$ \\
\hline 11 & True & $\begin{array}{l}\text { The bag has } \\
\text { more red } \\
\text { beads }\end{array}$ & Not true & $\begin{array}{l}\text { Written } \\
\text { explanation }\end{array}$ & Second bag & Equal numbers \\
\hline 12 & True & $\begin{array}{l}\text { Written } \\
\text { explanation }\end{array}$ & True & $\begin{array}{l}\text { Written } \\
\text { explanation }\end{array}$ & Second bag & $\begin{array}{l}\text { Written } \\
\text { explanation }\end{array}$ \\
\hline 13 & Not true & $\begin{array}{l}\text { By } \\
\text { calculation }\end{array}$ & Not true & $\begin{array}{l}\text { By } \\
\text { calculation }\end{array}$ & Equal Chances & By calculation \\
\hline 14 & True & $\begin{array}{l}\text { Written } \\
\text { explanation }\end{array}$ & True & $\begin{array}{l}\text { Written } \\
\text { explanation }\end{array}$ & Equal Chances & $\begin{array}{l}\text { Written } \\
\text { explanation }\end{array}$ \\
\hline 15 & True & $\begin{array}{l}\text { Written } \\
\text { explanation }\end{array}$ & True & $\begin{array}{l}\text { Written } \\
\text { explanation }\end{array}$ & Equal Chances & By calculation \\
\hline 16 & True & $\begin{array}{l}\text { Written } \\
\text { explanation }\end{array}$ & Not true & $\begin{array}{l}\text { Written } \\
\text { explanation } \\
\text { Calculation }\end{array}$ & Second bag & By calculation \\
\hline 17 & True & $\begin{array}{l}\text { Written } \\
\text { explanation }\end{array}$ & Not true & $\begin{array}{l}\text { Written } \\
\text { explanation }\end{array}$ & Second bag & Equal numbers \\
\hline 18 & True & $\begin{array}{l}\text { The bag has } \\
\text { more red } \\
\text { beads }\end{array}$ & True & $\begin{array}{l}\text { The bag has } \\
\text { more red } \\
\text { beads }\end{array}$ & Second bag & Equal numbers \\
\hline 19 & True & $\begin{array}{l}\text { By } \\
\text { calculation }\end{array}$ & Not true & $\begin{array}{l}\text { By } \\
\text { calculation }\end{array}$ & First and third bags & By calculation \\
\hline 20 & - & & - & & - & \\
\hline 21 & - & & True & $\begin{array}{l}\text { By } \\
\text { calculation }\end{array}$ & - & \\
\hline 22 & Not true & $\begin{array}{l}\text { By } \\
\text { calculation }\end{array}$ & Not true & $\begin{array}{l}\text { By } \\
\text { calculation }\end{array}$ & Equal Chances & By calculation \\
\hline
\end{tabular}




\begin{tabular}{|c|c|c|c|c|c|c|}
\hline 23 & Not true & $\begin{array}{l}\text { By } \\
\text { calculation }\end{array}$ & Not true & $\begin{array}{l}\text { By } \\
\text { calculation }\end{array}$ & - & \\
\hline 24 & True & & True & & Second bag & $\begin{array}{l}\text { Because they are } \\
\text { equal }\end{array}$ \\
\hline 25 & Not true & & Not true & & Equal Chances & By calculation \\
\hline \multirow[t]{2}{*}{26} & True & $\begin{array}{l}\text { The bag has } \\
\text { more red } \\
\text { beads then } \\
\text { green }\end{array}$ & true & $\begin{array}{l}\text { The bag } \\
\text { contains more } \\
\text { red beads } \\
\text { then green }\end{array}$ & Second bag & $\begin{array}{l}\text { It has equal } \\
\text { number of beads }\end{array}$ \\
\hline & $\begin{array}{l}\text { 14-true, 8-not } \\
\text { true }\end{array}$ & & $\begin{array}{l}\text { 10-true, } \\
\text { 14-not true }\end{array}$ & & $\begin{array}{l}\text { 11-second bag, } \\
\text { 11-equal chance }\end{array}$ & \\
\hline
\end{tabular}

Note: Most often students select the "true" answer because the bag contains more red beads thinking more red implies more probability, and they select the second bag because it has equal number of red and green beadsselecting a symmetric structure.

Table 7. Answers to probability questions (first year teachers-statistics class)

\begin{tabular}{|c|c|c|c|c|}
\hline Student no. & $\begin{array}{l}\text { 5-RED, } \\
\text { 2-Green }\end{array}$ & Explenation & $\begin{array}{l}\text { 5-RED,4-Green; } \\
\text { 5-RED,5-Green; } \\
\text { 4-RED,5-Green }\end{array}$ & Explenation \\
\hline 1 & true & calculation & Equal probability & calculation \\
\hline 2 & true & calculation & $?$ & - \\
\hline 3 & true & calculation & Third bag & $\begin{array}{l}\text { Sort of graphic } \\
\text { calculation }\end{array}$ \\
\hline 4 & not true & calculation & Second bag & calculation \\
\hline 5 & true & calculation & Second bag & calculation \\
\hline 6 & true & $?$ & Second bag & calculation \\
\hline 7 & true & calculation & Second bag & calculation \\
\hline 8 & true & calculation & Second bag & calculation \\
\hline 9 & true & calculation & Second bag & calculation \\
\hline 10 & true & More reds & Third bag & Bag $1 \& 3$ \\
\hline 11 & true & calculation & Third bag & calculation \\
\hline 12 & true & More reds & Second bag & $\begin{array}{l}\text { Written } \\
\text { explanation } \\
\text { regarding } \\
\text { number of } \\
\text { beads in bags }\end{array}$ \\
\hline 13 & true & $\begin{array}{l}\text { Written } \\
\text { explanation } \\
\text { regarding } \\
\text { number of } \\
\text { beads in } \\
\text { bags }\end{array}$ & Second bag & $\begin{array}{l}\text { Written } \\
\text { explanation } \\
\text { regarding } \\
\text { number of } \\
\text { beads in bags }\end{array}$ \\
\hline 14 & true & More reds & Second bag & $\begin{array}{l}\text { Numerical } \\
\text { equality }\end{array}$ \\
\hline 15 & true & More reds & Second bag & $\begin{array}{l}\text { Numerical } \\
\text { equality }\end{array}$ \\
\hline 16 & true & More reds & Second bag & $\begin{array}{l}\text { Numerical } \\
\text { equality }\end{array}$ \\
\hline 17 & & & & \\
\hline
\end{tabular}




18
19
20
21
22
23
24
25
26

$14 / 15$

$10 / 15,3 / 15$ third

bag

Note. Most often students select the "true" answer because the bag contains more red beads thinking more red implies more probability, and they select the second bag because it has equal number of red and green beadsselecting a symmetric structure.

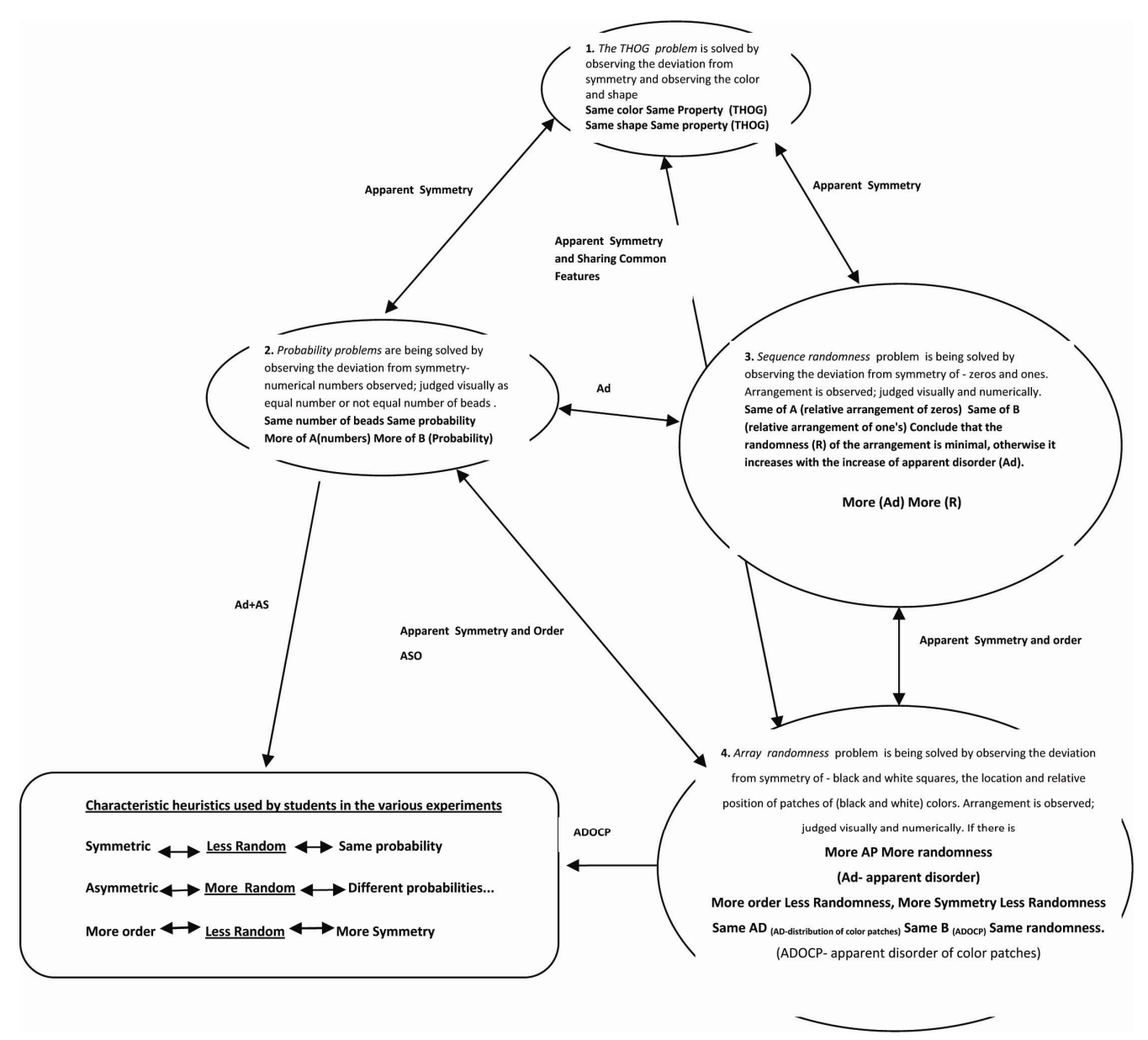

Figure 1. Summary of subjective randomness conception and heuristics

Note: Problem solving for the THOG problem probability problems of random arrangements of sequences and squares is most often related and is influenced by order and symmetry. Characteristically the solutions to these problems concerning sequences and array composition are related to their apparent symmetry which has the greatest influence on the rules and heuristics being used. Arrows indicate the most influential factor identified for solving these problems. 
The heuristics table above help establish the following symmetric and asymmetric relations among variables that characterize the decisions people take regarding the randomness of sequences arrays and structures in general:

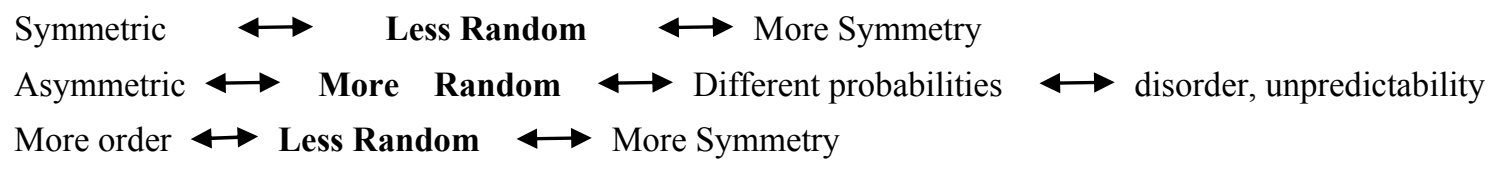

Obviously these subjective perceptions of randomness students have are not mathematically necessarily true. The heuristics described in this research are just a collection of observation of the subjective conception of randomness and related rules and heuristics for solving probability and randomness problem.

One of the claims is that mathematically randomness implies disorder; to see that this is not the case we look for example at the "chaos game" Barnsley(1993), which is generated by the throwing of a dice and results in a sequence of random numbers and it in turn can be shown to generates the Sierpinski triangle, and possibly the Sierpinski Tetrahedron and other fractals. This game of chance shows that mathematically randomness does not necessarily imply disorder because it results in the following Sierpinski triangle.

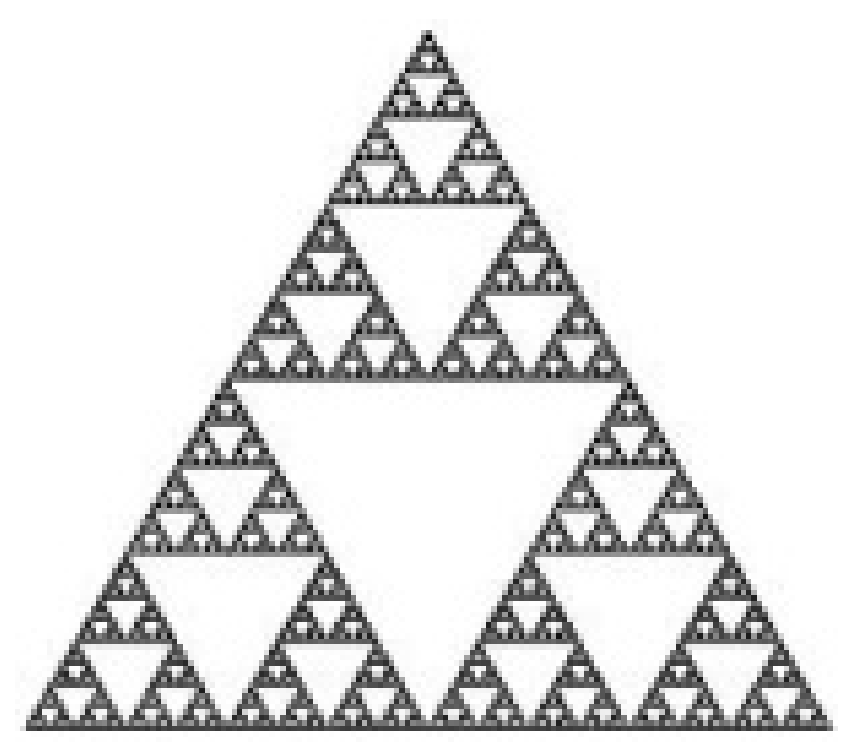

Figure 2. The Sierpinski triangle

We find then that for certain dynamic processes apparent randomness does not necessarily lead to mathematic disorder or structural disorder and therefore that asymmetry of processes also does not necessarily result in randomness. So we find that many of the characteristic problem-solving heuristics people use and those I have been describing in this research are conceptually false and mathematically incorrect and they are simply the cognitive misconceptions of people, characterizing their heuristics and subjective problem solving capabilities. These misconceptions are consistent with Hellman (1978) suggesting that randomness is interchangeable with indeterminism. But, as we have seen actually mathematically randomness does not necessarily imply disorder.

To Sum up, we have seen that subjective cognition of randomness is characterized by heuristics intertwined with randomness, symmetries, and asymmetries of sets of objects:

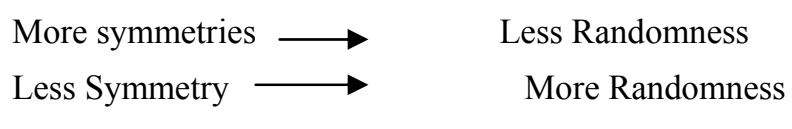

and

Dynamically Generated Random Sets $\longrightarrow$ Asymmetry

These subjective perceptions hold in many life situations as well as in mathematics and scientific settings. 


\section{References}

Anscombe, J., \& Aumann, R. (1963). A Definition of Subjective Probability. Ann. Math. Statist, 34(1), 199-205. http://dx.doi.org/10.1214/aoms/1177704255

Barnsley, M. (1993). Fractals Everywhere. Morgan Kaufmann.

Eagle, A. (2005). Randomness Is Unpredictability. British. J. phil. Sci. http://dx.doi.org/10.1093/bjps/axi138

Earman, J. (1986). A Primer on Determinism. Dorderecht: D. Reidel. http://dx.doi.org/10.1007/978-94-010-9072-8

Ekeland, I. (1988). Mathematics and the Unexpected. Chicago: Chicago University Press.

Evans, J. (2003). In two minds: Dual process accounts of reasoning's. Trends in Cognitive Sciences, 7, 459-454. http://dx.doi.org/10.1016/j.tics.2003.08.012

Falk, R. (1975). Perception of randomness. (Unpublished doctoral dissertation, in Hebrew, with English abstract). Hebrew University, Jerusalem, Israel.

Falk, R. (1981). Perception of randomness. (Unpublished doctoral dissertation, in Hebrew, with English abstract). Hebrew University, Jerusalem, Israel.

Falk, R., \& Knold. C. (1997). Making Sense of Randomness: Implicit Encoding as a Basis for Judgment. Psychological Review, 104(2), 301-318. http://dx.doi.org/10.1037/0033-295X.104.2.301

Griggs, R. A., \& Newstead, S. E. (1982). The role of problem structure in deductive reasoning task. Journal of Experimental Psychology: Learning, Memory, and cognition, 8, 297-307. http://dx.doi.org/10.1037/0278-7393.8.4.297

Griggs, R. A., \& Cox, J. R. (1982). The elusive thematic materials effect in Wason's selection task. British Journal of Psychology, 73, 407-420. http://dx.doi.org/10.1111/j.2044-8295.1982.tb01823.x

Griggs, R. A., \& Newstead, S. E. (1983). The source of intuitive errors in Wason's THOG problem. British Journal of Psychology, 74, 451-459. http://dx.doi.org/10.1111/j.2044-8295.1983.tb01877.x

Hellman, G. (1978). Randomness and Reality. In P. D. Asquith, \& I. Hacking (Eds.), PSA (Vol. 2, pp. 79-97). Chicago: University of Chicago Press.

Kolmogorov, A. (1968). Logical basis for information theory and probability theory. IEEE Transactions on Information Theory, 14(5), 662-664. http://dx.doi.org/10.1109/TIT.1968.1054210

McBeath, M., Schiano, D., \& Tversky, B. (1997). Three dimensional Bilateral symmetry bias in judgments of figural identity and orientation. Psychological Science, 8(3), 217-233. http://dx.doi.org/10.1111/j.1467-9280.1997.tb00415.x

Newstead, S. E., \& Griggs, R. A. (1992). Thinking about THOG: Source of error in deductive reasoning problem. Psychological research / Psycologische Forschung, 54(4), 299-305. http://dx.doi.org/10.1007/BF01358267

Schreiber, J. (2003). Cognitive difficulties of adolescents in solving probability tasks. (MA thesis, in Hebrew). Tel-Aviv Israel: Tel-Aviv University.

Schreiber, J. (2012). The Cognitive Processes of Probability Estimation in Random Sampling from Discrete Uniform Spaces. Journal of Educational and Developmental Psychology, 2(1). http://dx.doi.org/10.5539/jedp.v2n1p21

Smyth, M. M., \& Clark, S. E. (1986). My half -sister is a THOG: Strategic processes in reasoning task. British journal of psychology, 77, 275-287. http://dx.doi.org/10.1111/j.2044-8295.1986.tb02002.x

Wason, P. C. (1977). Self-Contradictions. In P. N. Johnson-Laird, \& P. C. Wason (Eds.), Thinking: Reading in cognitive science (pp. 114-128). Cambridge University Press. 


\section{Appendix \\ Questionnaires}

\section{$\underline{\text { Random sequence questionnaire }}$}

Based on an experiment I performed I wrote several sequences with zeros and ones, each sequence composed of 16 zeros and ones, 8 zeros and 8-ones. What can be said about the sequences in the list) are there any random sequences?
1) 0101010101010101
2) 1000111100011100
3)0001110001110011
4)
0000000111011111
5) 1100110011001100

Arrange the sequences from the more random to the least random, left to right, the order is:

explain your answer.

\section{Random array questionnaire}

Based on an experiment I performed I wrote several arrays with black and white squares, each array is composed of 50 white and 50 black squares. Please classify the arrays as random or less random.

1)

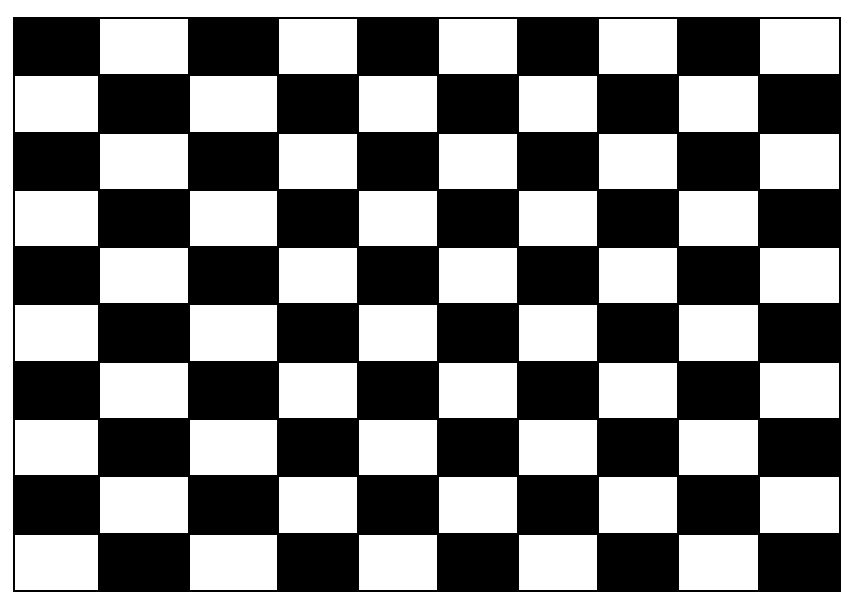

2)

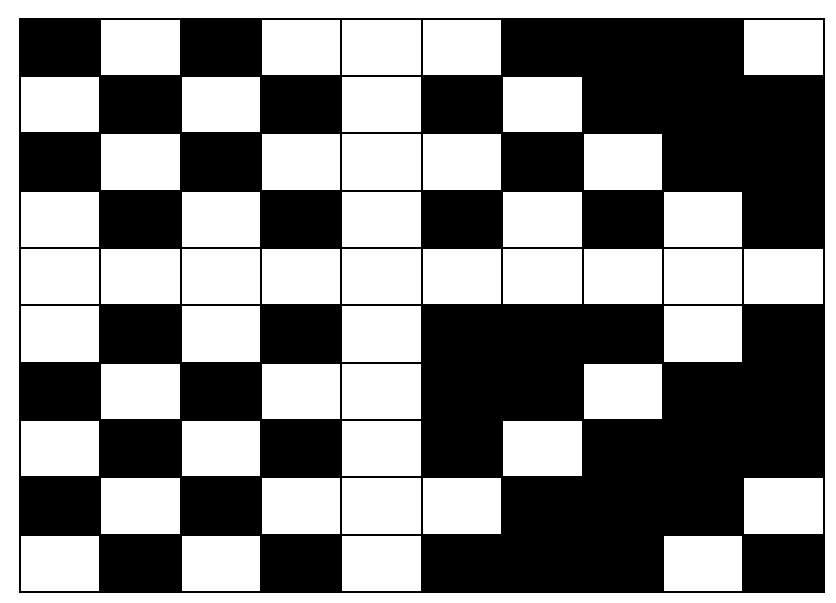


3)

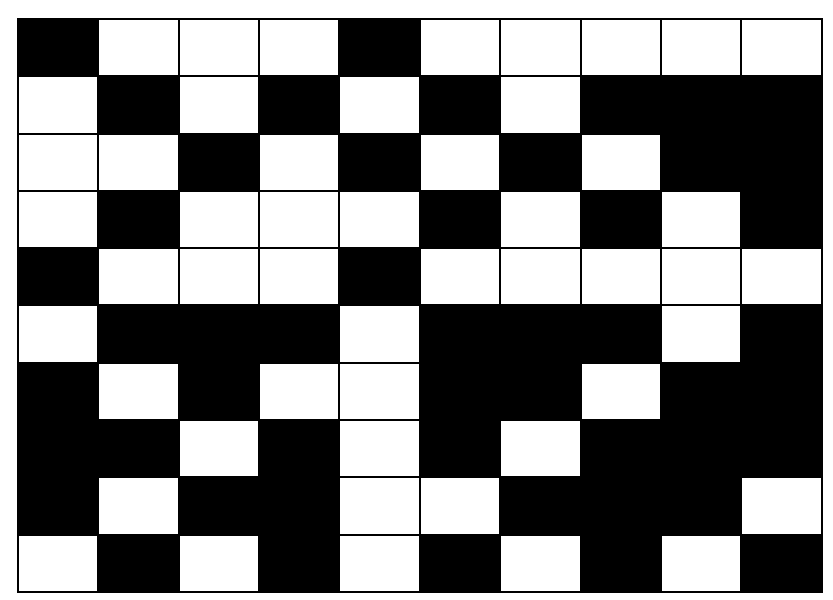

4)

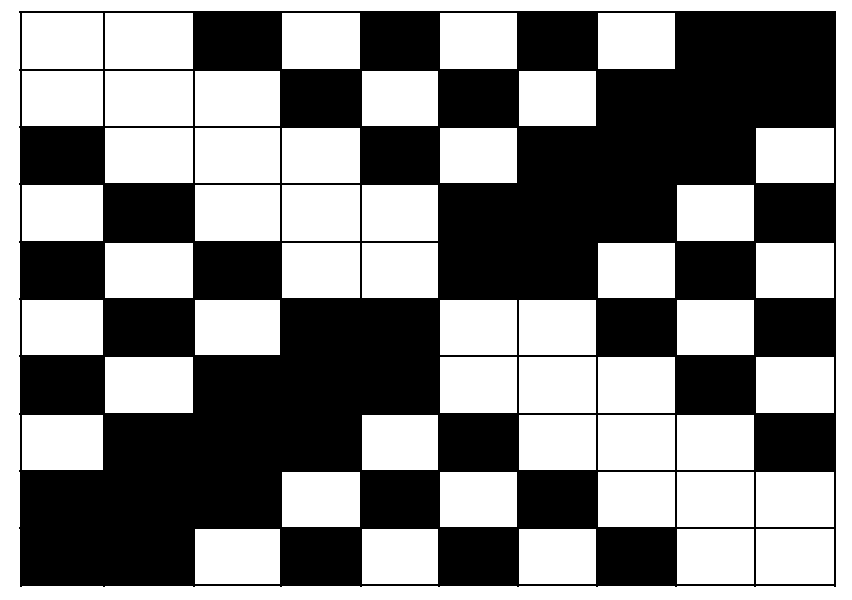

5)

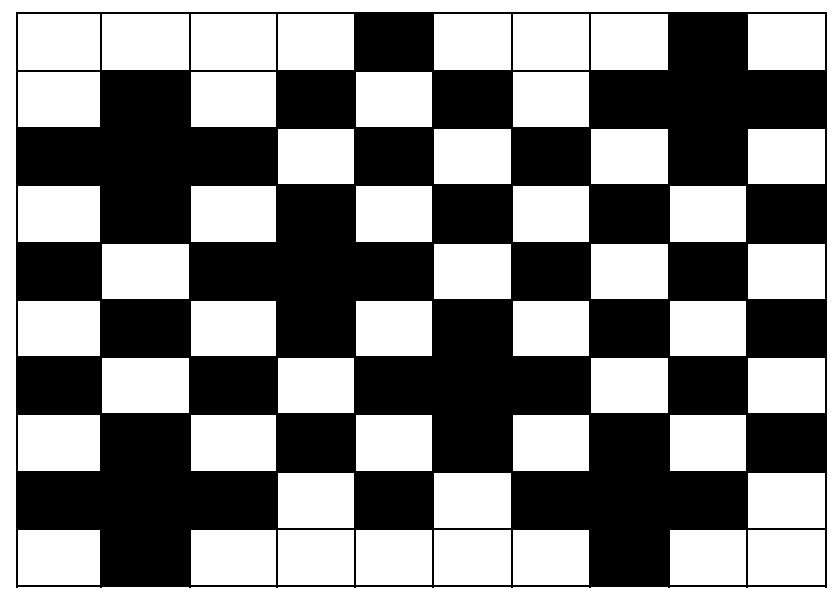


6)

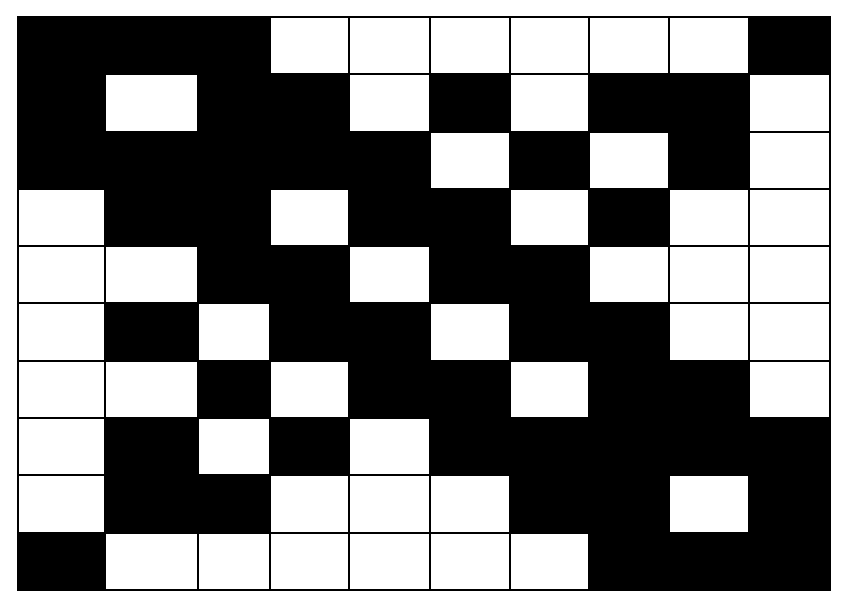

Arrange the arrays from the more random to the least random, left to right, the order is: , explain your answer.

\section{Copyrights}

Copyright for this article is retained by the author(s), with first publication rights granted to the journal.

This is an open-access article distributed under the terms and conditions of the Creative Commons Attribution license (http://creativecommons.org/licenses/by/3.0/). 